\title{
The online computer-assisted translation class getting faster target language
}

\author{
Henry Jackman ${ }^{1}$
}

\section{ARTICLE INFO}

Received: 9 August 2020

Revised: 19 September 2020

Accepted: 27 October 2020

\section{KEYWORDS}

CAT,

course platforms,

software functions,

target language,

technology,

translation class.

\begin{abstract}
Computer-assisted translation technology is complex and, in many cases, intimidating for students new to CAT software. Thus, CAT technology is best taught using a step-by-step approach with exercises first focusing on the basic features and then on more elaborate software functions (scaffolding). The goal is to equip students with the step-by-step instructions and screencast tutorials needed to complete exercises. Students gain further software experience by working on a larger text of their choice throughout the semester. They first prepare and format this source text for CAT tool use, and they then build a termbase and translate the source text into their target language. Finally, students write two essays reflecting on the advantages and disadvantages of using CAT software for producing their target texts. Translation students must be aware of the context in which translation memory tools are used and the impact that their use has on the translation itself.
\end{abstract}

Copyright $(\odot) 2021$ by The author(s). This is an open access article distributed under the terms of the Creative Commons Attribution (CC BY 4.0), which permits unrestricted use, distribution, and reproduction in any medium, as long as the original authors and source are cited. No permission is required from the authors or the publishers.

\section{Correspondence:}

8 Jackman, $\mathrm{H}$.

衰 St Lucia QLD 4072, Australia

$\checkmark$ hendry.jackman@uq.edu.au 


\section{INTRODUCTION}

Course design is the key to effective online learning and student engagement [1]. Online course platforms that are used for online course delivery, such as Desire2Learn and Canvas, allow instructors to conduct courses through (narrated) lectures, readings, screencast tutorials, class discussion fora, hands-on practice homework assignments, and quizzes. At the core of every online course is a well-organized online learning platform with a detailed syllabus and clear and complete course materials. A core element of any class is a clearly structured course syllabus. Compared with classes that are designed for on-site classroom delivery, syllabi for online classes need to be more detailed. Syllabi for online graduate-level translation classes must include a detailed description of the class requirements, schedules, due dates and deadlines for homework assignments [2].

Due to the constantly developing translation technology software, onsite and online CAT classes must be updated each year to reflect changes in the newest software versions and other new trends in translation technology. The online CAT course consists of 15 weekly modules, including lectures, readings, screencast tutorials, homework and final project assignments, a discussion forum component, and quizzes. While the online nature of the course allows students to complete activities at their own pace, time management is crucial as students can expect to spend about 9-12 hours a week on the course (depending on their comfort level with translation technology software). In the virtual CAT classroom, each course module spans one week focusing on one specific topic, from an introduction to CAT technology at the beginning of the semester to server-based translator/editor projects toward the end of the term.

The weekly topic is also considered in the discussion forum component of the class, where students compose answers to questions posed by the instructor or other students and engage in critical discussions. There are clear guidelines for discussion posts on what constitutes a critical reflection. These are outlined on the course syllabus. Comments like "good point" etc. are not counted as critical reflection posts. Perhaps most importantly, engaging in the discussion forum is a way for students to reflect on their learning [3]. The instructor answers questions directly in the forum and provides a wrap-up document at the end of each week, summarizing the findings and lessons learned from each module. Students benefit by learning from each other and helping fellow students by providing tips on how to tackle software errors etc. Teaching translation should always include plenty of practice translation assignments. The same is true for teaching translation technology.
The weekly hands-on CAT software homework assignments have been considered the most important element of the online CAT class by all graduate translation students who have taken the course evaluation survey. Over the course of four semesters (2016-2019), 57 Translation graduate students have taken the online CAT class. All of the survey respondents (46 of the 57 graduate students) remarked that the practical CAT software exercises were among the most beneficial course components [4]. Each week, students work on translations and terminology databases using CAT software and learn how to effectively use CAT tools through handson successive tasks. The instructor provides detailed personal feedback on these assignments on a weekly basis to make sure that students are using CAT software correctly. For the instructor, this often includes troubleshooting CATrelated software user errors, rebooting the remote workstation that students are accessing via remote desktop protocol (RDP) or troubleshooting errors with the students using Skype screen sharing or exchanging screenshots that illustrate the software error students are experiencing.

Since the class is taught entirely online, the instructor and the students discuss and solve any CAT technologyrelated question and system errors in a dedicated troubleshooting forum on the online course platform or via real-time Skype screen sharing. Problems that frequently occur include user errors, such as misplacing files in SDL Trados Studio's file/folder structure or system errors, such as temporary bugs that can occur after system updates that cause the software to stop functioning correctly. Students often post screenshots of software error messages and CAT-related questions in the asynchronous discussion board that are then answered by the instructor or other students in a timely manner [5]. Alternatively, students may contact the instructor during Skype office hours, when problems are solved via real-time Skype screen sharing. The instructor then guides students through the troubleshooting process by accessing the student's workstation, checking the system for accurate functionality, and going over solutions to software troubles with students online and in real time.

This way, students learn CAT technology troubleshooting skills that are highly beneficial as they prepare to enter the translation industry as freelance translators who often collaborate with clients and translation agencies entirely online. Finally, the online setting lends itself to incorporating group work to foster a collaborative environment and an interactive online teaching and learning experience. Online teachers must take full advantage of the online course platform and all its integrated components (lectures, readings, video screencasts, tutorials, homework exercises), as well as online meeting rooms (Blackboard Collaborate) to foster active student participation. Instructor feedback is highly important in the online classroom and especially when teaching the use of

Vol. 15 | No. 1 | 2021 | Pages: 1-9 
complex software programs. Students usually receive feedback within one or two days of submitting homework exercises or quizzes [6]. The discussion forum also creates a space where students can ask questions, clarify doubts, troubleshoot software issues, and share interpretations of assigned readings.

Discussions in the online forum, online meetings using tools such as Blackboard Collaborate, as well as Skype office hours with screen sharing, provide an opportunity for students to interact with the instructor and classmates. The course is designed to teach future translators the main features of translating and editing using the latest versions of SDL Trados Studio and memoQ. This includes the use of translation memory (TM) and alignment features, as well as terminology database (TB) creation and effective terminology management using market-leading CAT tools [7].

Students also obtain certifications for SDL and memoQ as part of the course which is beneficial as they enter the translation market. Each week, we focus on a different CAT tool topic that relates not only to practical aspects of using the software but also to areas that are crucial in the translation industry, including translation rates, translation memory ownership and copyright, and the compatibility of different CAT systems. In addition to gaining hands-on translation practice using the newest versions of SDL Trados Studio, SDL Multiterm, and memoQ, students learn the important skill of troubleshooting technology issues in an online environment. Throughout the semester, students work on weekly CAT tool exercises and they work on a final translation project of their choice. This way, they build a termbase and a translation memory in a specialization they are interested in, such as medical, legal or technical translation. At the end of the class, small groups of students investigate and present on a translation technology of their choice (e.g. a CAT tool not discussed in class, a project management (PM) software etc.). Throughout the course students also take quizzes which prepare them for taking the SDL and memoQ certifications. In all, students enhance their knowledge of CAT tools by working on both weekly and semester-long exercises and by collaborating and communicating online with their instructor and their classmates via the course platform [8].

\section{METHODS}

The reflection instructions were created with that goal in mind, and ask students to observe the advantages and disadvantages of terminology management and translation memory use [9]. In their reflection essays, students pointed out that there were benefits to working with a side-by-side editor in a CAT program and that formatting is automatically carried over from the ST to the TT segments. They noted that using termbases helped to keep terminology consistent while translating repetitive and specialized source texts. Generally, the termbase function was viewed very favourably. Students were also encouraged to outline potential downsides of CAT tool use as these were also discussed in class. Here, many students mentioned that there is a risk of translators automatically accepting fuzzy matches and full matches that are suggested by the CAT tool's TM, even if the matches don't fit the context. The segmentation removes individual sentences from their contexts, which has often been noted as a disadvantage by students in the class. Students also wrote about technology issues they occasionally encountered, such as software freezes or crashes. Quality management in translation is discussed in the course as part of various steps in the translation lifecycle, from file preparation, research, and terminology management to proofreading and editing. In the fora, students discuss how to address these potential downsides of CAT tool use, for example by using the preview function to see target segments in their full context [10]. Through practice exercises, in which students are paired up as teams of translators and editors working in the same language pairs, students gain practice applying quality management guidelines to the computerassisted translation process. One important step to assuring translation quality in specialized translation is careful terminology management.

\section{DISCUSSIONS}

In the following, I will describe my step-by-step approach to teaching CAT technology using the module on terminology management in week 5 as an example. The module consists of a lecture on terminology, readings, homework assignments, and a discussion component focusing on the importance of terminology in specialized translation. In addition, students post questions each week in the separate optional forum dedicated to solving and troubleshooting software issues. The hands-on practice exercise for week 5 focuses on creating an SDL MultiTerm termbase for translating the final project source text.

Naturally, as a means of quality management, terminology work needs to be done before any attempt at translating a text. Proper terminology-management is time-consuming. Yet, terminology work gains increasing significance in (specialized) translation. Many international institutions and large corporations employ specialized terminologists to achieve high-quality terminology management. Standardized and wellmaintained terminology is a key to successful communication, internationalization, and translation [11]. Through the readings, the lecture, and most importantly the homework assignment for the week, students learn and experience that terminology management is worth the effort and why it plays such an 
important role in the translation industry. Terminology management enables all parties involved in the translation lifecycle to use terminology correctly and consistently. Sauberer (Director of the International Network for Terminology) estimates that about 40 percent of translation time is terminology research: Documented terminology reduces time spent on re-research [12].

In addition, terminological changes in large translation projects can be very costly. Clarifying terminology before working on a project reduces query time later on [13]. Above all, in specialized translation, key terminology must be translated correctly and consistently. Dunne defines defective terminology as "terminology that is incorrect, inconsistent and/or ambiguous". Translators and terminologists must avoid defective terminology by conducting proper terminology research before translating a text and by documenting that terminological research in terminology databases or termbases (TBs). Proper terminology management is a main factor in mitigating risks in the translation process that can arise due to defective terminology work. Thus, teaching translation-oriented terminology research and management must be integrated into the Translation classroom (CAT courses, PM courses, translation workshops) to train future translators and terminologists and provide them with the skillset that is necessary in the professional translation industry [14].

During the week when we focus on terminology management, students work on building termbases for their specialized final project source text with repetitive terminology that needs to be translated consistently. Students first extract key terminology from their final project source texts and then build termbases based on that text corpus. The course goal for the week is to learn proper terminology research and documentation as it relates to translation studies. Here are four steps on the way to your own terminology: 1) define a terminology concept (organization and extent of the glossary, sources, tools, participants); 2) extract the terminology in the source language; 3) translate the terminology, and 4) distribute/manage the terminology.

According to Austermühl, "translation is a knowledge-based activity" and "terminological competence is translator competence". A systemic concept-oriented approach to terminology management allows translators to gain knowledge in their area of specialization, and thereby achieve a higher level of competence in its specific terminology. In addition, terminology databases provide a "real-world context" and include context examples in both the SL and the TL. In contrast to bilingual dictionaries, translation-oriented terminology databases are corpus-based: the underlying terminology is extracted from relevant parallel texts and specialized parallel text corpora. Translator termbases are ideally corpus-based and concept-based [15]. Students are required to structure their termbases using a concept-based approach, meaning that one term represents one concept.

Existing translation policy research often focuses on cultural matters, particularly when dealing with unequal power relationships between languages. This not only underpins the research on translation flows as inspired by the sociologically oriented approaches of [16]. A significant number of case studies also thematize cultural inequalities and their relationship with translation policy. For instance, culture planning in smaller cultures is the topic who describes the development of 'low code' Slovene culture beside 'high code' German culture. Translation from Slavic cultures was encouraged to actively change the existing cultural and linguistic power relationships. Cultural dominance patterns can be actively opposed by importing innovative, but similarly strong literary influences. Another example of such import by a smaller culture is the attempt of the 'Young Estonia' movement to extend the influence of Romance literature in early 20th century Estonia. However, the policy has also been adopted by larger language areas, which aimed to renew their cultural sources. This was for instance the case of Germany in the late 19th and early 20th century. It tried to move away from the dominant cultural influence of France by importing Scandinavian and Nordic literature on a large scale by means of translation [17].

Ožbot's approach is an interesting case in point, as she explicitly relates the culture planning policy to political and economic power relationships: "translating is never a neutral act, but a process in which relations of linguistic, cultural, political and economic power are at play". Whereas such cultural power struggles between larger language areas are never existential, this is much more the case in unequal power relationships. Ožbot mentions the example of bilingual environments such as Ireland, "in which the two interacting languages were extremely unequal in terms of their power relations" (108) and translating could not be considered a neutral act. Cultural and language policy are closely interwoven through translation or non-translation in such cases.

Indeed, even when a (non-)translation policy does not specifically aim to achieve political goals, it can be highly ideologically and politically sensitive. Christina Schäffner (2016/2008) deals with the 2006 discussion in the UK media about the costs and the political desirability of providing translation in immigration matters. Within our discipline, translation practice and translation policy are usually associated with positive terms such as support and bridgebuilding. However, the dominant discourse in the UK media discussion was totally different. Besides being criticized for the high costs 
involved, highly generous translation facilities for immigrants were also associated with a barrier to learning English, a danger to social cohesion and a higher risk of failed integration. The whole discourse was "rather a discourse about immigration, integration, citizenship, national identity" [18].

A central element in almost all language policies is the decision whether to translate or not, or what to translate or not. As a consequence, every state or institution with a multilingualism policy is in practice also dealing with a translation policy. Such policies and practices can be either top-down, imposed by authorities, or bottom-up, generated by everyday multilingual situations in contemporary cities, for instance - for more examples of both types. Top-down policies in particular are often associated with the attempts of states to boost national integration policies, both from a cultural and a political point of view. Translation in such cases is used as an agent defending hegemonic national interests, as stated. However, national interests do not necessarily mean homogenizing a state linguistically or culturally. State borders can be used or abused to minoritize a language group that is all but minoritarian at a different level.

This is for instance the case for the small German-language population in Belgium - German being the third official language in Belgium after Dutch and French. Although there exists a legal framework guaranteeing many rights, the German-speaking Belgians are often dissatisfied about its "nonimplementation in (some) governmental and linguistic practice(s)" [19]. National borders (of Belgium, in this case) apparently can lead to an insufficient implementation of language and translation rights even for the speakers of the largest linguistic community in the European Union, as the German-speaking area of Belgium borders on areas housing almost 100 million other German speakers in Europe, namely in Germany, Switzerland, Austria and Luxemburg. This example shows the relative status of power relationships between languages, because they are co-determined by the language and translation policy of the state in which they operate. The case below also is to be understood within such a complex power framework.

Although Estonian is the majority's (and only official) language within the Republic of Estonia, the language and translation policy toward the large Russian-language minority cannot be discussed without taking into account the position of neighboring Russia. In this sense, we can make very similar cases for Estonia(n) and Latvia(n). Translation policy also especially plays a role in this process in Central and Eastern Europe, where "the dynamics of bordering and rebordering" is ongoing after the collapse of the Soviet Union.
Drawing on Spolsky's work on language policy, distinguishes three levels of translation policy. We will apply his taxonomy when analyzing and assessing the case studies discussed in this article: translation management: explicit top-down policy referring to the decisions about use or non-use of translation; translation practice: practices as a result of the abovementioned policy, but also more implicit bottom-up practices based on the needs; translation beliefs: beliefs of a community about the value of translation under specific circumstances. The next section briefly describes the historical and demographic circumstances of Estonia over the past century, before investigating two institutional websites in more detail, using González Núñez' translation policy terminology.

Estonia is a country in Northeastern Europe with a population of 1.3 million people. After centuries of Danish, Swedish, German, and Russian rule, Estonia attained independence from the Russian Empire in 1918. In 1940 it was forcibly incorporated into the USSR and regained its freedom only in 1991, with the collapse of the Soviet Union. Languages spoken in Estonia reflect the ethnic groups living in the country, and have therefore changed according to the sociopolitical situation. In 1919, Estonian, a Uralic language related to Finnish, became the state language of the newly independent country. During the Soviet occupation and as a result of russification policy, the proportion of Estonians in the overall population fell from $97.3 \%$ in 1945 to $61.5 \%$ in 1989 . Russian was made the second language in education, and the first in several functional spheres, such as industrial plants, factories, offices, state institutions and service bureaus, which were created in parallel with the Estonian ones. The Estonian language was reinstated as the constitutional state language in 1988. After regaining independence in 1991, the greatest change in the language policy was related to the status and use of Russian in the Estonian education system: learning Estonian is compulsory for all students, while at the level of higher education, the language of tuition is mainly Estonian, with diminishing options for studying in Russian. Russian is still widely used in some parts of Estonia (mostly in the Northeastern part of the country and in some parts of the capital city Tallinn), but has no official status.

According to the results of the 2011 Population and Housing Census, the largest ethnic groups are Estonians (68.7\%), Russians (24.8\%), Ukrainians (1.7\%), Belarusians and Finns (both less than 1\%). Estonian as the official language is the native language of $68.5 \%$ of the population. The most prevalent minority native language is Russian, spoken by $29.6 \%$ of the population. There is a total of 25 languages with over one hundred native speakers in Estonia (Statistics Estonia, 2012). The majority of the population of Estonia is multilingual, speaking at least one foreign language in addition to their mother tongue (usually a more widely spoken language, such as 
Russian, English or German). European integration has increased the interest in English among Estonian and Russian speakers, which has given rise to the English language in the Estonian education system and in Estonian society at large.

Since Estonia regained its independence, language legislation has developed inconsistently. Language use and language management are described in various laws, most clearly in the Constitution of the Republic of Estonia the Language Acts the Development Plans of the Estonian Language (2004-2010 and 2011-2020), and the Estonian Foreign Languages Strategy (2009-2017). Translation policy as such has not been legislated in Estonia; the use of foreign languages and translation has been implicitly included in all of the above-mentioned laws and legislations. The implicit presence of translation policy is discussed in more detail in the paragraphs below.

At the very general level, the principles of language policy are stated in the Constitution of the Republic of Estonia (1992). The preamble and the Article 6 of the Constitution stipulate that Estonia has one state language -Estonian- which has to be preserved and developed by all people and institutions of Estonia. Although Estonian is the official language of government agencies and local authorities, other languages and different mother tongues are also accepted. The use of foreign languages (and the implicit presence of translation) is mentioned in Article 52 of the Constitution, which stipulates that "the use of foreign languages, including the languages of national minorities, in government agencies, in courts and in pre-trial procedure is provided by law". All quotes from laws in this article use the English text as digitally available in the State Gazette. The Electronic State Gazette (Riigi Teataja) is the central database and official online publication for Estonian legislation. Since 2010, all national legal acts are made public only in electronic form in Estonia. The English translations published.

This article protects the interests of minorities and gives certain local authorities the right to decide on the use of the language in internal affairs. The Constitution of the Republic of Estonia has been translated into English and Russian. The English version is digitally available via the State Gazette. The Russian translation was published on the Legal Aid webpage of Eesti Õigusbüroo OÜ. The most important legislative act concerning the language (and translation) policy in Estonia is the Language Act. It regulates the use of the Estonian language and foreign languages in oral and written administration, public information and service. According to subsection 8(1) of the current Language Act (2011), "[e]veryone has the right to access the public administration in the Estonian language in oral or written form in state agencies, including the foreign representations of Estonia, local government authorities, at the offices of notaries, bailiffs and sworn translators and their bureaus, cultural autonomy bodies and other agencies, companies, non-profit associations and foundations registered in Estonia." The words translate, translation and translator are mentioned 24 times across 10 sections.

As the purpose of the Act is to ensure the use of the Estonian language as the main language for communication in all spheres of public life, the word translation mostly means translation from a foreign language into Estonian. Regarding translation policy, the most relevant are sections $12,16,18,34$ and 35. Section 12 "Access to public administration in foreign languages" regulates the role of translation in any communication with a state agency or local government authority and stipulates: "If an application, request or other document submitted to a state agency or local government authority is in a foreign language, the agency has the right to require the person who submits the document to submit the translation of the document into Estonian, $[\ldots]$ ".

Translation is also mentioned in section 16 "Language of information", where it says in subsection 16(2): "The translation of the text into a foreign language may be added to public signs, signposts, business type name and outdoor advertisements" and in subsection 16(5): "At public events the organiser shall ensure the translation into Estonian of the essential information in a foreign language." Section 18 "Translation of foreign language text of audio visual works, television and radio programmes and advertisements" stipulates: "Upon public performance and transmission of audio visual works, including programmes and advertisements, the provider of the audio visual media service or a company shall ensure that a foreign language text shall be accompanied by an adequate translation into Estonian in form and content". Sections 34-37 consider violations of requirements for the use of the Estonian language and their consequences. The Language Act has also been translated into English and published in the State Gazette. The Russian translation is available on the Legal Aid webpage of Eesti Õigusbüroo OÜ in the State Gazette are unofficial texts - they do not have legal force and one cannot rely on them in judicial or any other official proceedings. In Estonia, legislation has legal force only in Estonian. Retrieved from https://www.riigiteataja.ee/en/, accessed 26.12.2018. Eesti Õigusbüroo OÜ, in cooperation with the Ministry of Justice, provides legal assistance free of charge and under favorable terms to people residing in Estonia. In cooperation with the legal aid portal juristaitab.ee, 52 Russian translations of the law have been made available in the State Gazette. The translations of the laws are for informational purposes only and have no legal effect.

Strategic planning of the development of the Estonian language was begun in 1998 by the Ministry of Education. In 2004, the Government of the Republic of Estonia adopted the first 
Development Strategy of the Estonian Language 2004-2010 (DSEL) which covered four areas: Estonian as the native language, Estonian as the second language, Estonian abroad, and multilingualism, including foreign languages. The followup document, the Development Plan of the Estonian Language 2011-2017 (DPEL), was prepared by the Ministry of Education and Research, and adopted in 2009. In 2018, the government decided to extend the DPEL until the end of 2020, and started to prepare the Estonian Language Development Plan 20212035. The DSEL was translated into English, Russian, Finnish, and Hungarian. The DPEL is available both in print and on the Internet in Estonian and in English.

The current Development Plan of the Estonian Language (DPEL) is a strategic document in the language domain. It ensures the functioning of the Estonian language as the state language in all spheres of life as well as the teaching, research, development, and protection of the Estonian language. The main objective of the DPEL is to provide a uniform strategic and legal basis for the sustainable development of the Estonian language (DPEL, 2011, p. 8). Translation is mentioned in only a few specific cases: translation in court proceedings, translation of information provided to consumers, the promotion of translation studies, the development of CAT tools and machine translation, the training of interpreters and translators. The most relevant parts of the DPEL related to translation matters are quoted below (emphasis by the authors):

- Estonian is also the language of court proceedings; legal acts regulate the use of other languages in court proceedings, as well as translation of documents and the use of an interpreter. The Consumer Protection Act stipulates that any information provided to the consumer has to be presented in Estonian; an Estonian-language translation is required for instruction manuals in a foreign language.

- Study of language contacts and language change: to promote translation studies.

- Measure 3: Development of the language-technological support for the Estonian language. Actions: to work out modules of a translator's workbench, terminologist's workbench, and lexicographer's workbench, which could be modified if necessary; to create a machinetranslation system, where all existing devices for the processing of Estonian are adapted for the needs of machine translation; to develop large-scale parallel corpora for the needs of statistical machine translation (EU documents, major areas of international communication for Estonian scientists).

- It is important for the development of the Estonian language that the Estonian language should be well represented both in Europe and around the world (including through qualified interpreters and translators, academic studies of the Estonian language abroad, and various types of cooperation in language matters), as well as good Estonian and foreign-language proficiency among Estonian residents.

- Estonian institutions of higher education train interpreters and translators; according to estimates, the number of interpreters and translators is insufficient, but there is no accurate survey of needs.

- Measure 11: development of the Estonian language in the context of foreign languages and ensuring its international representation. Action: to determine the need for interpreters and translators and to train them in the required numbers.

The aim of the development plan is to ensure the preservation of the Estonian language, whereas foreign languages and translation are mentioned mostly in the context of academic studies, the international representation of the Estonian language or in the sphere of public administration.

The purpose of the measures of the Estonian Foreign Languages Strategy 2009-2015 (extended until 2017) is to provide Estonian people with better opportunities in a globalizing world and to increase their competitiveness in the labor market. Interestingly, this strategy is only available in the Estonian language. The Strategy comprises thematic principles as well as guidelines for foreign language learning, teaching and assessment. The learning of foreign languages has always been stressed in Estonian public discourse, but this is the first document that deals with foreign language policy and foreign language learning at government level. The goals of the Estonian Foreign Languages Strategy are to stimulate the motivation of Estonian residents to learn foreign languages, to offer different opportunities for foreign language learning and to enhance the quality of language teaching.

Translation as such plays a relatively marginal role in this document and only concerns the following issues: the importance of the training of language professionals (including translators and interpreters) at universities (p. 9), the importance of setting criteria for foreign language skills at different jobs (e.g. sworn translators) (p. 10) and to conduct research in the area of foreign languages (including translation studies) (p. 21). In brief, translation is only mentioned with regard to the learning and teaching of foreign languages, as well as research in this field. Such a limited view on translation as a by-product of foreign language learning reflects the - for modern Translation Studies, very old-fashioned - view that translation skills are no different from foreign language skills, or that the knowledge of a foreign language equals translation skills. 


\section{CONCLUSION}

Teaching translation technology online holds many challenges as it includes troubleshooting software errors entirely online. The virtual CAT classroom can only function well when both students and the instructor are actively communicating via the course platform, online meeting rooms, Skype, or communication channels within the CAT server software. Students need to be proactive and raise software-related questions and make the instructor aware of potential technological issues before the homework due date. The instructor must respond to student questions in a timely manner and offer at least twice as many Skype office hours as for a regular (online) class. In order to teach translation technology in the virtual classroom successfully, CAT exercises must be tested on the students' remote workstations in advance and the course content must be developed in its entirety before course launch to ensure a positive learning experience for students.

\section{Conflict of Interest Statement}

The author declared no conflicts of interest related to the material presented in this article.

\section{REFERENCES}

[1] Al-Mansour, N. S. (2012). The effect of computerassisted instruction on Saudi University students' learning of English. Journal of King Saud University-Languages and Translation, 24(1), 51-56. https://doi.org/10.1016/j.jksult.2009.10.001

[2] Bedi, A., Dolan, M., Magennis, E., Lipman, J., Buly, R., \& Kelly, B. T. (2012). Computer-assisted modeling of osseous impingement and resection in femoroacetabular impingement. Arthroscopy: The Journal of Arthroscopic \& Related Surgery, 28(2), 204-210. https://doi.org/10.1016/j.arthro.2011.11.005

[3] Candel-Mora, M. Á. (2015). Comparable corpus approach to explore the influence of computer-assisted translation systems on textuality. Procedia-Social and Behavioral Sciences, 198, 67-73. https://doi.org/10.1016/j.sbspro.2015.07.420

[4] Delpech, E. M. (2014). Comparable corpora and computer-assisted translation. John Wiley \& Sons.

[5] Dorafshar, A. H., Brazio, P. S., Mundinger, G. S., Mohan, R., Brown, E. N., \& Rodriguez, E. D. (2014). Found in space: computer-assisted orthognathic alignment of a total face allograft in six degrees of freedom. Journal of Oral and Maxillofacial Surgery, 72(9), 1788-1800. https://doi.org/10.1016/j.joms.2014.01.016

[6] Folz, R. J., \& Crapo, J. D. (1994). Extracellular superoxide dismutase (SOD3): tissue-specific expression, genomic characterization, and computer-assisted sequence analysis of the human EC SOD gene. Genomics, 22(1),

$162-171$ https://doi.org/10.1006/geno.1994.1357

[7] González-Rubio, J., \& Casacuberta, F. (2014). Costsensitive active learning for computer-assisted translation. Pattern Recognition Letters, 37, 124-134. https://doi.org/10.1016/j.patrec.2013.06.007

[8] Ivanova, O. (2016). Translation and ICT competence in the globalized world. Procedia-Social and Behavioral Sciences, 231, 129-134. https://doi.org/10.1016/j.sbspro.2016.09.081

[9] Jansen, J., Schreurs, R., Dubois, L., Maal, T. J., Gooris, P. J., \& Becking, A. G. (2018). The advantages of advanced computer-assisted diagnostics and three-dimensional preoperative planning on implant position in orbital reconstruction. Journal of Cranio-Maxillofacial Surgery, 46(4), $715-721$. https://doi.org/10.1016/j.jcms.2018.02.010

[10] Khezrlou, S., Ellis, R., \& Sadeghi, K. (2017). Effects of computer-assisted glosses on EFL learners' vocabulary acquisition and reading comprehension in three learning conditions. System, 65, 104-116. https://doi.org/10.1016/j.system.2017.01.009

[11] Lavid, J., Arús, J., DeClerck, B., \& Hoste, V. (2015). Creation of a high-quality, register-diversified parallel (English-Spanish) corpus for linguistic and computational investigations. Procedia-Social and Behavioral Sciences, 198 , 249-256. https://doi.org/10.1016/j.sbspro.2015.07.443

[12] Lin, H. H., \& Lo, L. J. (2015). Three-dimensional computer-assisted surgical simulation and intraoperative navigation in orthognathic surgery: a literature review. Journal of the Formosan Medical Association, 114(4),

300-307. https://doi.org/10.1016/j.jfma.2015.01.017

[13] Maier-Hein, L., Mountney, P., Bartoli, A., Elhawary, H., Elson, D., Groch, A., ... \& Stoyanov, D. (2013). Optical techniques for 3D surface reconstruction in computerassisted laparoscopic surgery. Medical image analysis, 17(8), 974-996 https://doi.org/10.1016/j.media.2013.04.003

[14] Marzban, A. (2011). Improvement of reading comprehension through computer-assisted language learning in Iranian intermediate EFL students. Procedia Computer Science, 3, 3-10. https://doi.org/10.1016/j.procs.2010.12.003

[15] Rahimi, M., \& Yadollahi, S. (2011). Foreign language learning attitude as a predictor of attitudes towards computer-assisted language learning. Procedia Computer Science, 3, 167-174. https://doi.org/10.1016/j.procs.2010.12.029 
[16] Rindal, D. B., Rush, W. A., Schleyer, T. K., Kirshner, M., Boyle, R. G., Thoele, M. J., ... \& Huntley, C. L. (2013). Computer-assisted guidance for dental office tobaccocessation counseling: a randomized controlled trial. American journal of preventive medicine,44(3), 260-264. https://doi.org/10.1016/j.amepre.2012.10.023

[17] Serpil, H., Durmuşoğlu-Köse, G., Erbek, M., \& Öztürk, Y. (2016). Employing computer-assisted translation tools to achieve terminology standardization in Institutional Translation: Making a case for higher education. Procedia-Social and Behavioral Sciences, 231, 76-83. https://doi.org/10.1016/j.sbspro.2016.09.074

[18] Willer, J., Rossbach, A., \& Weber, H. P. (1998). Computer-assisted milling of dental restorations using a new CAD/CAM data acquisition system. The Journal of prosthetic dentistry, 80(3), 346-353. https://doi.org/10.1016/S0022-3913(98)70136-2

[19] Williams, R. J., Bibb, R., Eggbeer, D., \& Collis, J. (2006). Use of CAD/CAM technology to fabricate a removable partial denture framework. The Journal of prosthetic dentistry, 96(2),

96-99. https://doi.org/10.1016/j.prosdent.2006.05.029

[20] Yeager, M. S., Cook, D. J., \& Cheng, B. C. (2014). Reliability of computer-assisted lumbar intervertebral measurements using a novel vertebral motion analysis system. The Spine Journal, 14(2), 274-281. https://doi.org/10.1016/j.spinee.2013.10.048 